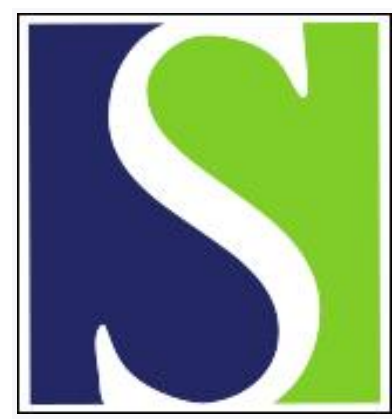

Scand J Work Environ Health 2007;33(1):29-36

https://doi.org/10.5271/sjweh.1061

Issue date: 31 Feb 2007

Employment status, mental disorders and service use in the working age population

by Honkonen T, Virtanen M, Ahola K, Kivimäki M, Pirkola S, Isometsä E, Aromaa A, Lönnqvist J

Affiliation: Finnish Institute of Occupational Health, Topeliuksenkatu 41 a A, Fl-00250 Helsinki, Finland. teija.honkonen@ttl.fi

Refers to the following texts of the Journal: $2000 ; 26(2): 169-177$

2005;31(1):3-14

The following articles refer to this text: 2008;34(2):81-82;

2021;47(3):208-216

Key terms: alcohol use disorder; anxiety disorder; depression; employment situation; employment status; mental disorder; population-based study; prevalence; service use; treatment contact; working age population

This article in PubMed: www.ncbi.nlm.nih.gov/pubmed/17353962

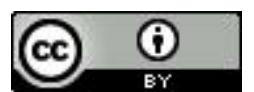




\title{
Employment status, mental disorders and service use in the working age population
}

\author{
by Teija Honkonen, PhD, ${ }^{1}$ Marianna Virtanen, PhD, ${ }^{1}$ Kirsi Ahola, MA, ${ }^{1}$ Mika Kivimäki, PhD, ${ }^{1,2}$ Sami \\ Pirkola, PhD, ${ }^{3,4}$ Erkki Isometsä, PhD, ${ }^{3,5}$ Arpo Aromaa, PhD, ${ }^{6}$ Jouko Lönnqvist, PhD ${ }^{3,5}$
}

\begin{abstract}
Honkonen T, Virtanen M, Ahola K, Kivimäki M, Pirkola S, Isometsä E, Aromaa A, Lönnqvist J. Employment status, mental disorders and service use in the working age population. Scand $J$ Work Environ Health 2007;33(1):29-36.
\end{abstract}

\begin{abstract}
Objectives This study examined the association between employment status and specific DSM-IV (Diagnostic and Statistical Manual for Mental Disorders, IVth edition) depressive, anxiety and alcohol use disorders and the association between employment status and service use for these disorders.

Methods As part of the representative population-based "Health 2000 Study" of Finns aged 30 years or over, 3440 employed, 429 unemployed, and 820 economically inactive persons of working age (30-64 years) participated in a comprehensive health examination, including the standardized Composite International Diagnostic Interview.

Results The risk of mental disorders was generally higher among the unemployed and the economically inactive than among the employed. The respective odds ratios were 1.79 [95\% confidence interval $(95 \% \mathrm{CI})$ 1.26-2.54] and 1.54 (95\% CI 1.06-2.25) for depressive disorders, 2.68 (95\% CI 1.85-3.89) and 2.53 (95\% CI 1.76-3.65) for anxiety disorders, and 2.58 (95\% CI 1.82-3.65) and 1.43 (95\% CI 0.91-2.22) for alcohol use disorders. Similar results were obtained for most of the specific categories of these disorders. Among the persons with anxiety disorders, the odds for treatment contact were 2.35 (95\% CI 1.06-5.23) times higher for the unemployed than for the employed after control for disorder severity. For those with an alcohol use disorder, the corresponding odds ratio was 3.51 (95\% CI 1.23-9.98).

Conclusions Common mental disorders are less prevalent among the employed than among unemployed and economically inactive people. Among those with anxiety or alcohol use disorders, service use is less common among the employed than among the unemployed. This difference is not explained by the severity of the clinical state.
\end{abstract}

Key terms alcohol use disorder; anxiety disorder; depression; employment situation; population-based study; prevalence; treatment contact.

Mental disorders are burdensome because of their high prevalence and chronicity, early age of onset, and the resulting serious impairment (1-3). The cost of mental disorders, particularly depression, to employers in terms of lost workdays and reduced productivity is substantial (4-6). In Finland, mental disorders were the most common cause of disability pensions being granted in 2004 (7).
The epidemiology of mental disorders has been widely studied (8-16), but relatively few studies have examined the association between employment status and mental disorders (11-16). In the survey of the International Consortium in Psychiatric Epidemiology (ICPE), employed respondents had the lowest 12-month estimated comorbid prevalence in five of the seven countries studied (15). The European Study of the

1 Finnish Institute of Occupational Health, Helsinki, Finland.

2 Department of Psychology, University of Helsinki, Helsinki, Finland.

3 Department of Mental Health and Alcohol Research, National Public Health Institute, Helsinki, Finland.

4 National Research and Development Centre for Welfare and Health, Helsinki, Finland.

5 Department of Psychiatry, University of Helsinki, Helsinki, Finland.

6 Department of Health and Functional Capacity, National Public Health Institute, Helsinki, Finland.

Reprint requests to: Dr T Honkonen, Finnish Institute of Occupational Health, Topeliuksenkatu 41 a A, FI-00250 Helsinki, Finland. [E-mail: teija.honkonen@ttl.fi] 
Epidemiology of Mental Disorders (ESEMeD) described the 12-month prevalence of DSM-IV (Diagnostic and Statistical Manual for Mental Disorders, IVth edition) mental disorders in six European countries and found that unemployment was related to a higher risk of mental disorders in general, and mood and alcohol disorders in particular (16). In addition, unemployed people have been shown to use primary and mental health care more frequently than employed people (17), and they also have increased hospitalization rates (18). However, it is not known whether the increased service use simply reflects the poorer health of the unemployed (19).

Several aspects of the association between employment status and mental disorders have remained unclear. Previous studies have either ignored the association between employment status and specific diagnostic categories of mood, anxiety, or substance use disorders or have not controlled for potential confounding factors such as socioeconomic status or have not reported service use. The aim of our present study was to investigate the association between employment status and specific DSM-IV depressive, anxiety, and alcohol use disorders among a sample of the working age population. We controlled the associations for several potential confounding factors, including socioeconomic status, as indicated by occupational grade. We also examined the association between employment status and service use for depressive, anxiety, and alcohol use disorders, taking into account the severity of the clinical state.

\section{Study population and methods}

\section{Study design and data collection}

A multidisciplinary epidemiologic health survey, the Health 2000 Study, took place in 2000-2001 in Finland. The two-stage stratified cluster sample was representative of the Finnish population aged 30 years or over (14, $20,21)$. The strata were the five university hospital districts, each serving about one million inhabitants and differing in several features related to geography, economic structure, health services, and the sociodemographic characteristics of the population (20-22). First, the 15 largest cities were included with a probability of one. Next, within each of the five districts, all 65 other areas were sampled, with the probability proportionalto-population-size (PPS) method applied. Finally, from each of these 80 areas, a random sample of people was drawn from the National Population Register.

Data collection started in August 2000 and was completed in March 2001. The participants were interviewed at home (phase 1), where they were given a questionnaire to be returned at the time of the clinical health examination approximately 4 weeks later (phase 2). During the home interview the respondents also received an information leaflet, and their written informed consent was obtained.

The original sample comprised 8028 persons aged 30 years or over. Fifty-one persons of the 8028 had died before the interview. Thus 7977 persons were alive on the day of the first phase of the survey. Of the original sample, 6986 (87\%) were interviewed. The number participating in the health examination was 6770 (84\%). A structured mental health interview, the Composite International Diagnostic Interview (CIDI), was performed with $6038(75 \%)$ persons, of whom 33 were excluded due to being clearly unreliable on the basis of mental retardation or self-expressed intention to lie. The total number of reliably performed interviews was 6005 $(75 \%)$.

Of the original sample, 5871 persons were of working age (30 to 64 years). These working age persons comprised the base population of our study. Of this sample, 5152 (88\%) persons were interviewed, 4935 (84\%) persons returned the questionnaire, and 4886 (83\%) participated in the health examination, including the CIDI interview. The total number of reliably performed CIDI interviews was 4706 , amounting to $80 \%$ of the total working age sample. Details of the methodology used for the Health 2000 Study have been published earlier $(14,21)$.

Compared with those who participated in the CIDI interview, those who did not were younger (45 versus 46 years, $\mathrm{P}<0.001)$, more often men $(56 \%$ versus $48 \%$, $\mathrm{P}<0.001$ ), unmarried ( $39 \%$ versus $24 \%, \mathrm{P}<0.001$ ), bluecollar workers ( $43 \%$ versus $35 \%, \mathrm{P}<0.001$ ), or self-employed (17\% versus $14 \%, \mathrm{P}<0.001)$, unemployed $(14 \%$ versus $9 \%, \mathrm{P}<0.001)$ persons or economically inactive ( $28 \%$ versus $17 \%, \mathrm{P}<0.001$ ). For the Beck Depression Inventory (BDI) scores, there were no statistically significant differences between those who participated in the CIDI interview and those who did not. Among the nonparticipants, the mean scores of the BDI were significantly higher for the unemployed (mean 8.8) and the economically inactive (mean 9.4) than for the employed (mean 4.8) $(\mathrm{P}<0.001)$. This finding is in agreement with the differences between employment statuses among the participants. [See the Results section.]

\section{Study population}

The final study population of 4706 persons comprised 2469 (weighted percentage 50.2\%) women and 2237 (weighted percentage 49.8\%) men (table 1). The mean age of the participants was 46.4 (SE 0.14) years. Of the study population, 3440 (73.6\%) were employed, 429 $(9.1 \%)$ were unemployed, and 820 (17.3\%) were economically inactive. The group of 820 economically 
Table 1. Distributions of sociodemographic factors among the study population ( $\mathrm{N}=4706){ }^{\text {a }}$

\begin{tabular}{|c|c|c|c|c|c|c|c|c|}
\hline \multirow[t]{2}{*}{ Factor } & \multicolumn{2}{|c|}{ Total working age sample b } & \multicolumn{2}{|c|}{ Employed $^{\mathrm{b}}$} & \multicolumn{2}{|c|}{ Unemployed b } & \multicolumn{2}{|c|}{ Economically inactive ${ }^{b}$} \\
\hline & $N$ & $\%$ & $\mathrm{~N}$ & $\%$ & $\mathrm{~N}$ & $\%$ & $\mathrm{~N}$ & $\%$ \\
\hline \multicolumn{9}{|l|}{ Gender } \\
\hline Male & 2237 & 49.8 & 1700 & 51.8 & 182 & 44.7 & 345 & 43.5 \\
\hline Female & 2469 & 50.2 & 1740 & 48.2 & 247 & 55.3 & 475 & 56.5 \\
\hline \multicolumn{9}{|l|}{ Age } \\
\hline 30-34 years & 667 & 13.8 & 544 & 15.4 & 48 & 10.8 & 74 & 8.5 \\
\hline $35-44$ years & 1410 & 29.4 & 1171 & 33.5 & 124 & 27.9 & 106 & 12.4 \\
\hline 45-54 years & 1580 & 34.3 & 1301 & 38.5 & 152 & 35.9 & 125 & 15.8 \\
\hline 55-64 years & 1049 & 22.6 & 424 & 12.6 & 105 & 25.4 & 515 & 63.3 \\
\hline \multicolumn{9}{|l|}{ Marital status } \\
\hline Married & 3544 & 75.5 & 2691 & 78.2 & 249 & 57.7 & 604 & 73.5 \\
\hline Unmarried & 1145 & 24.5 & 749 & 21.8 & 180 & 42.3 & 216 & 26.5 \\
\hline \multicolumn{9}{|l|}{ Occupational grade } \\
\hline Upper white-collar & 1137 & 24.3 & 954 & 27.6 & 44 & 10.4 & 139 & 17.0 \\
\hline Lower white-collar & 1280 & 27.0 & 936 & 26.8 & 119 & 27.2 & 225 & 27.7 \\
\hline Blue-collar & 1605 & 34.9 & 1024 & 30.4 & 242 & 57.4 & 339 & 42.6 \\
\hline Self-employed & 635 & 13.9 & 514 & 15.2 & 21 & 5.0 & 100 & 12.7 \\
\hline
\end{tabular}

a Employment status missing in 17 cases.

b The data were weighted to take into account the sampling design and to reduce bias due to nonresponse.

inactive included 67 students, 118 housewives, 617 persons on disability pension, and 18 other persons.

\section{Employment status}

Information on employment status was collected in the home interview. Employment status was divided into the following three groups: the employed, the unemployed, and those economically inactive. The economically inactive group included housewives, students, and those on disability pensions, among others. The term "nonemployed" referred to a combined group of the unemployed and the economically inactive persons. Employment status was missing in 17 cases.

\section{Mental health assessment}

The mental health interview was performed at the end of the comprehensive health examination using the standardized CIDI interview, which has been shown to be a valid assessment measure of common mental nonpsychotic disorders (23). A Finnish translation of the German, computerized version of the CIDI (M-CIDI) was used $(14,24)$. This program uses operationalized criteria for DSM-IV diagnoses (25) and allows the estimation of DSM-IV diagnoses for major mental disorders. The 21 interviewers were primarily nonpsychiatric health care professionals. They had received 3-4 days of training in the administration of the CIDI interview from psychiatrists and physicians who themselves had been trained by a trainer authorized by the World Health Organization.

The available DSM-IV diagnoses were grouped into categories of depressive, anxiety, and alcohol use disorders. The category of depressive disorders included the last 12 months' diagnoses of a major depressive disorder or dysthymia. Anxiety disorders included panic disorder (with or without agoraphobia), generalized anxiety disorder, social phobia, phobia not otherwise specified, and agoraphobia (without panic disorder). The participants with alcohol use disorders included those fulfilling the diagnostic criteria of alcohol dependence or abuse during the last 12 months. The results have been reported using DSM-IV criteria without diagnostic hierarchy rules for mental disorders.

The severity of the clinical state was assessed as follows: among persons with depressive disorders (major depressive disorders and dysthymia), the original BDI was used $(26,27)$. The assessment consists of 21 items with Likert-type response scales scored from 0 to 3 . At least 14 items had to be completed for the assessment to be accepted. A mean score for the depressive symptoms was then calculated. In a subgroup of persons with a major depressive disorder, and also among persons with anxiety disorders, the severity of the clinical state was assessed according to symptoms reported in the CIDI interview. Among the persons with alcohol use disorders, the severity of the clinical state was assessed by the amount of alcohol consumed. The participants reported their habitual frequency and amount of beer, wine, and spirit consumption in the questionnaire. This information was transformed into grams of alcohol per month.

\section{Service use for mental health and alcohol problems}

The use of services for mental health problems was assessed by asking the participants if they had visited any 
services on the following list, either as an outpatient or inpatient, for problems with mental health during the past 12 months: community health centers, occupational health services, psychiatric outpatient clinics or mental health centers, outpatient clinics for substance use problems, family counseling centers, private outpatient appointments with physicians or psychologists, psychiatric hospitals, other hospitals, rehabilitation centers, and other services. The use of services for alcohol problems was assessed by asking the participants if they had visited a psychiatrist, physician, nurse, or other professional for problems with alcohol during the past 12 months.

\section{Sociodemographic factors}

The following information on sociodemographic characteristics was collected in the home interview: gender, age, marital status (married or co-habiting versus others), and occupational grade. The categories of occupational grade were based on the occupational classification of Statistics Finland (28) as follows: white-collar worker, lower white-collar worker, blue-collar worker, and self-employed. For the unemployed and the economically inactive, the occupational grade was coded on the basis of previous employment or education. There was a small group of participants $(\mathrm{N}=32)$ for whom occupational grade could not be coded.

\section{Statistical analysis}

The descriptive statistics on the prevalences of mental disorders in relation to background variables were analyzed by cross-tabulations and chi-square tests. In order to test the differences in the severity of depressive symptoms (as measured by the BDI score) between persons in different employment situations, a one-way analysis of variance (ANOVA) was used.

Binary logistic regression models were used to calculate adjusted odds ratios (OR) and their 95\% confidence intervals $(95 \% \mathrm{CI}$ ) for mental disorders among persons in different employment situations. A corresponding analysis was run for the association between the employment situation and treatment contact among persons with a depressive, anxiety or alcohol use disorder. In models of treatment contacts, we additionally adjusted for the severity of the clinical state of the participants.

Weighting adjustment and sampling parameters were used in all of the analyses to account for the survey design complexities, including clustering in a stratified sample $(20,21)$. A complex sampling design such as ours can influence variance estimates of both population averages and regression coefficients, and therefore standard statistical methods based on simple random sampling are not adequate, either in analyzing descriptive statistics or in regression modeling. In contrast, weighting adjustment and sampling parameters allow the translation of sample data to population averages, as expressed by weighted percentages, means, and odds ratios. We used procedures (CROSSTABS, REGRESS and RLOGIST) of the SAS/SUDAAN program (SAS Inc, Gary, NC, USA) for this purpose.

\section{Results}

\section{Mental disorders in relation to sociodemographic fac- tors}

The prevalence of specific depressive, anxiety, and alcohol use disorders are presented in tables 2-4. Depressive and anxiety disorders were more common among the women than among the men $(9.2 \%$ and $5.2 \%$, $\mathrm{P}<0.001 ; 6.3 \%$ and $4.5 \%, \mathrm{P}=0.004$, respectively), whereas alcohol use disorders were more common among the men than among the women $(10.1 \%$ and $1.9 \%, \mathrm{P}<0.001$, respectively). There was no difference in the prevalence of depressive and anxiety disorders between various age categories. The prevalence of alcohol use disorders decreased with age $(\mathrm{P}=0.007)$. All of the disorders were more common among those unmarried than among those married (all $\mathrm{P}<0.001$ ).

Table 2. Depressive disorders among the working age sample by employment status $(\mathrm{N}=4689)$. ( $\mathrm{OR}=0 \mathrm{dds}$ ratio, $95 \% \mathrm{Cl}=95 \%$ confidence interval)

\begin{tabular}{|c|c|c|c|c|c|c|c|c|c|c|c|c|}
\hline \multirow[t]{2}{*}{ Group } & \multicolumn{4}{|c|}{ Major depressive disorder a } & \multicolumn{4}{|c|}{ Dysthymia a } & \multicolumn{4}{|c|}{ Any depressive disorder ${ }^{a}$} \\
\hline & $\mathrm{N}$ & $\%$ & $\mathrm{OR}^{\mathrm{b}}$ & $95 \% \mathrm{Cl}$ & $\mathrm{N}$ & $\%$ & $\mathrm{OR}^{\mathrm{b}}$ & $95 \% \mathrm{Cl}$ & $\mathrm{N}$ & $\%$ & $\mathrm{OR}^{\mathrm{b}}$ & $95 \% \mathrm{Cl}$ \\
\hline Employed & 187 & 5.3 & 1.00 &.. & 57 & 1.6 & 1.00 & .. & 225 & 6.4 & 1.0 &.. \\
\hline Unemployed & 42 & 9.5 & 1.78 & $1.20-2.64$ & 21 & 4.9 & 2.64 & $1.46-4.76$ & 52 & 11.9 & 1.79 & $1.26-2.54$ \\
\hline Economically inactive & 41 & 5.0 & 1.11 & $0.73-1.69$ & 36 & 4.5 & 3.69 & $2.11-6.42$ & 64 & 7.9 & 1.54 & $1.06-2.25$ \\
\hline All & 270 & 5.6 & .. & .. & 114 & 2.4 & .. & .. & 341 & 7.1 & .. & .. \\
\hline
\end{tabular}

a The data were weighted to take into account the sampling design and to reduce bias due to nonresponse.

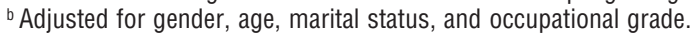


Table 3. Anxiety disorders among the working age sample by employment status ( $N=4689)$. (NOS = not otherwise specified, $\mathrm{OR}=0 \mathrm{dds}$ ratio, $95 \% \mathrm{Cl}=95 \%$ confidence interval)

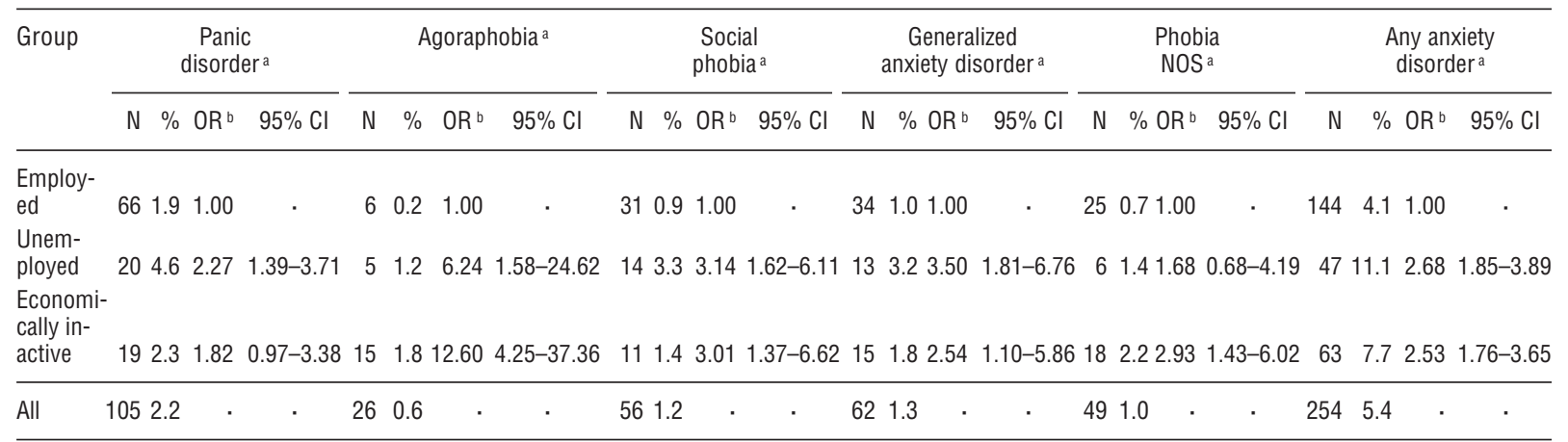

a The data were weighted to take into account the sampling design and to reduce bias due to nonresponse.

${ }^{\mathrm{b}}$ Adjusted for gender, age, marital status, and occupational grade.

Table 4. Alcohol use disorders among the working age sample by employment status $(\mathrm{N}=4689)$. ( $\mathrm{OR}=0 \mathrm{dds}$ ratio, $95 \% \mathrm{Cl}=95 \%$ confidence interval)

\begin{tabular}{|c|c|c|c|c|c|c|c|c|c|c|c|c|}
\hline \multirow[t]{2}{*}{ Group } & \multicolumn{4}{|c|}{ Alcohol abuse ${ }^{\text {a }}$} & \multicolumn{4}{|c|}{ Alcohol dependence a } & \multicolumn{4}{|c|}{ Any alcohol use disorder ${ }^{2}$} \\
\hline & $\mathrm{N}$ & $\%$ & $O R^{b}$ & $95 \% \mathrm{Cl}$ & N & $\%$ & $\mathrm{OR}^{\mathrm{b}}$ & $95 \% \mathrm{Cl}$ & $\mathrm{N}$ & $\%$ & $\mathrm{OR}^{\mathrm{b}}$ & $95 \% \mathrm{Cl}$ \\
\hline Employed & 48 & 1.4 & 1.00 & . & 141 & 4.2 & 1.00 & . & 158 & 4.7 & 1.00 & . \\
\hline Unemployed & 15 & 3.6 & 2.37 & $1.32-4.23$ & 45 & 10.8 & 2.55 & $1.76-3.70$ & 49 & 11.7 & 2.58 & $1.82-3.65$ \\
\hline Economically inactive & 15 & 1.9 & 2.32 & $1.12-4.82$ & 31 & 3.8 & 1.14 & $0.70-1.84$ & 39 & 4.8 & 1.43 & $0.91-2.22$ \\
\hline All & 78 & 1.7 & & . & 217 & 4.7 & & . & 246 & 5.4 & & . \\
\hline
\end{tabular}

a The data were weighted to take into account the sampling design and to reduce bias due to nonresponse.

${ }^{\mathrm{b}}$ Adjusted for gender, age, marital status, and occupational grade.

\section{Mental disorders by employment status}

The prevalence of depressive disorders varied according to the employment status (table 2). The risk of a major depressive disorder was higher for the unemployed than for the employed, and the risk of dysthymia was higher among the unemployed and economically inactive than among the employed. There were also significant differences in the prevalences of specific categories of anxiety disorders between employment statuses (table 3). The risks of agoraphobia, social phobia, and a generalized anxiety disorder were higher among the unemployed and the economically inactive than among the employed. The risk of panic disorder was higher for the unemployed and the risk of phobia (not otherwise specified) was higher for the economically inactive than for the employed.

As shown in table 4, employment status and alcohol use disorders showed an association with each other. The risk of alcohol abuse was higher for both the unemployed and the economically inactive than for the employed, whereas the risk of alcohol dependence was higher for the unemployed than for the employed. There was no significant interaction between gender and employment status in association with depressive, anxiety, or alcohol use disorders.

\section{Service use for mental disorders by employment status}

Altogether $32 \%$ of the employed, $47 \%$ of the unemployed, and $44 \%$ of the economically inactive persons with depressive disorders had visited health services due to their mental health problems during the past 12 months. The probability of service use was higher for the unemployed than for the employed (table 5). Among the depressive persons, a statistically significant difference in the severity of the clinical state (BDI) was found between the categories of employment status ( $\mathrm{F}=10.8$, $\mathrm{P}<0.001$ ), the highest score being attained by the economically inactive persons and the lowest by the employed. The severity of the clinical state was also associated with the probability of treatment contact $(\mathrm{P}=0.004)$. When the severity of the clinical state (a continuous BDI sum score) was entered into the logistic regression model, the association between service use and employment status was attenuated (table 5). Similar results were obtained for a subgroup of persons with a major depressive disorder after adjustment for the number of symptoms in the CIDI interview.

About one-third of the employed (31\%) and economically inactive (34\%) persons with anxiety disorders had visited health services during the past 12 months due to their mental health problems, whereas about half 
Table 5. Treatment contact during the previous 12 months among the working age sample of persons with DSM-IV mental disorders. [DSM-IV = Diagnostic and Statistical Manual for Mental Disorders (IV edition), OR = odds ratio, $95 \% \mathrm{Cl}=95 \%$ confidence interval]

\begin{tabular}{|c|c|c|c|c|c|c|}
\hline \multirow[t]{2}{*}{ Type of disorder } & \multicolumn{6}{|c|}{ Treatment contact ${ }^{\mathrm{a}}$} \\
\hline & $\mathrm{N}$ & $\%$ & $O R^{b}$ & $95 \% \mathrm{Cl}$ & $O R^{c}$ & $95 \% \mathrm{Cl}$ \\
\hline \multicolumn{7}{|l|}{ Depressive disorders } \\
\hline Employed & 73 & 32.3 & 1.00 & . & 1.00 & . \\
\hline Unemployed & 25 & 47.1 & 1.93 & $1.01-3.68$ & 1.65 & $0.84-3.26$ \\
\hline Economically inactive & 28 & 43.9 & 1.88 & $0.91-3.92$ & 1.46 & $0.71-3.02$ \\
\hline All & 126 & 36.8 & . & . & . & . \\
\hline \multicolumn{7}{|l|}{ Anxiety disorders } \\
\hline Employed & 44 & 30.6 & 1.00 & . & 1.00 & . \\
\hline Unemployed & 23 & 48.0 & 2.08 & $0.97-4.44$ & 2.35 & $1.06-5.23$ \\
\hline Economically inactive & 21 & 33.5 & 1.66 & $0.77-3.57$ & 1.87 & $0.88-3.99$ \\
\hline All & 88 & 34.6 & . & . & . & . \\
\hline \multicolumn{7}{|l|}{ Alcohol use disorders } \\
\hline Employed & 20 & 12.4 & 1.00 & . & 1.00 & . \\
\hline Unemployed & 17 & 34.1 & 3.68 & $1.31-10.37$ & 3.51 & $1.23-9.98$ \\
\hline Ecoomically inactive & 6 & 15.4 & 2.01 & $0.60-6.80$ & 1.98 & $0.59-6.66$ \\
\hline All & 43 & 17.2 & . & . & . & . \\
\hline
\end{tabular}

a The data were weighted to take into account the sampling design and to reduce bias due to nonresponse.

b Odds ratios adjusted for gender, age, marital status, and occupational grade.

'Odds ratios adjusted for gender, age, marital status, occupational grade, and severity of clinical state (in depressive disorders by the Beck Depression Inventory, in anxiety disorders by the Composite International Diagnostic Interview, and in alcohol use disorders by the amount of alcohol consumption).

$(48 \%)$ of the unemployed had done so (table 5). In a group of persons with anxiety disorders, there was no statistically significant difference in the severity of clinical state between the various categories of employment status $(\mathrm{F}=0.2, \mathrm{P}=0.857)$. The severity of the disorder was associated with a higher probability of treatment contact $(\mathrm{P}<0.001)$. After adjustment for severity, the odds of treatment contact was 2.4 times higher for the unemployed than for the employed (table 5).

Altogether $12 \%$ of the employed persons with an alcohol use disorder had visited health services during the past 12 months, compared with $34 \%$ of the unemployed and $15 \%$ of the economically inactive. The probability of treatment contact was higher for the unemployed than for the employed (table 5). With regard to the monthly amount of alcohol consumed among the persons with an alcohol use disorder, there was no statistically significant difference between the various categories of employment status $(\mathrm{F}=0.7, \mathrm{P}=0.485)$. Higher alcohol consumption was weakly associated with a higher probability of treatment contact $(\mathrm{F}=3.0, \mathrm{P}=0.085)$. When the level of alcohol consumption was entered into the logistic regression model, the association between employment status and service use for alcohol problems persisted (table 5). This association also remained after comorbidity with psychiatric disorders or any limiting long-term illness was controlled.

\section{Discussion}

In this sample of the Finnish working age population aged 30 to 64 years, the risk of depressive, anxiety, and alcohol use disorders was generally higher among the nonemployed (those unemployed and those economically inactive) than among the employed after control for several confounding factors. Similar results were obtained for most of the specific categories of these disorders. The National Psychiatric Morbidity Survey of Great Britain also found that both the unemployed and economically inactive had a higher 1-week prevalence of neurotic disorders than the employed (11), and in the Netherlands Mental Health Survey and Incidence Study (NEMESIS) mental disorders were the least common among people in paid employment (12). In the Australian National Survey of Mental Health and Well-Being, employed persons had lower rates for all of the psychiatric disorders (13). However, in none of these studies was the association between specific diagnostic categories and employment status reported.

Work and employment appear to represent prohealth factors and may protect against or alleviate depression $(29,30)$. According to the social causation hypothesis, employment influences health by contributing to social status and power, as well as to economic independence, social support, and self-esteem. According to the selection hypothesis, health status can result in changes in employment status. Unhealthy people are more likely to become unemployed (31) and more unlikely to become re-employed (32). Our results confirmed the association between unemployment and mental disorders, but due to the cross-sectional study design it was not possible to draw conclusions about the causality (33). Our findings of poor mental health among unemployed people may reflect the adverse effects of unemployment, but the reverse is also possible (ie, that those with poorer mental health were more likely to be excluded from the labor market).

Previous studies have revealed that only a minority of people with mental disorders in the general population receives treatment for these disorders $(19,34)$. In developed countries, $36 \%$ to $50 \%$ of serious cases have been shown to be untreated (19). Moreover, the quality of care appears not to be adequate either at the level of primary care $(35,36)$ or psychiatric care $(37)$. In Finland, local authorities are responsible for the provision of various mental health services for residents. Visits to public health centers or specialized mental health centers are the principal sources of outpatient treatment for people with mental health problems. In addition, most employers provide their employees with various medical services. In spite of good access to public health care, in a recent Finnish study, only $59 \%$ of even those suffering from the most severe 
major depressive episodes had used health services for depression (38).

In a recent report of the Organisation for Economic Co-operation and Development, the employed population in Finland was suggested to have better access to general practitioners due to occupational health care than the nonemployed (39). However, in line with previous studies $(17,18)$, our results show that the probability of treatment contact for mental disorders is higher for the unemployed than for the employed. Among those with depressive disorders, the unemployed had a worse clinical state than the employed, and this finding explained the association between employment status and treatment contact. Among those with anxiety or alcohol use disorders, we found no evidence that unemployed persons had a more serious disorder than employed persons, and, after adjustment for disorder severity, the unemployed still had a higher probability of treatment contact. These results may reflect a link between access to social benefits and service contact among unemployed persons suffering from mental disorders. The unemployed may also have more time to visit health care services than those employed. It is also possible that, in spite of good access to occupational health services, a fear of job loss and stigma may hinder the help seeking of those employed due to mental problems.

\section{Study strengths and limitations}

The use of data from the Finnish Health 2000 Study has several strengths. The study sample of 4689 persons represented the entire Finnish 30- to 64-year-old population, and the participation rate was very good. A total of $80 \%$ participated. Therefore, the results can be generalized to the Finnish working population in the age range of 30 to 64 years. The questionnaire measures, the CIDI interview, the estimates for the severity of clinical state, and the examination protocols were all selected on the basis of standardized, generally accepted recommendations and nationally established practices. The M-CIDI interview has been found to be valid and reliable in assessments of mental disorders $(10,19,24)$.

A nonresponse analysis revealed that, in terms of the severity of the clinical state, as assessed with the BDI, there was no difference between the participants and the nonparticipants with respect to the CIDI interview. Among the nonparticipants, mental health (BDI) was better among the employed than among the nonemployed, as was the case among the participants. These data suggest that major bias due to nonresponse was unlikely in our study.

Unfortunately, in the Health 2000 Study, the CIDI interview did not include young adults of 18 to 29 years of age, and therefore the whole working age population was not represented. The category of economically inactive represents a rather heterogeneous group, including those on disability pension, housewives, and students. However, the small number of housewives and students prevented stratified analyses. Thus findings regarding this group are difficult to interpret. Furthermore, data on service use and employment status were limited to self-reports and thus vulnerable to recall bias. Future studies might benefit from a multi-method assessment complementing employment status and service use with register data and case records of health care services. Furthermore, prospective studies with very large sample sizes are needed to shed light on the development process between employment status and mental disorders.

\section{Concluding remarks}

In conclusion, this study from a representative nationwide population of Finns 30 to 64 years of age shows that common depressive, anxiety, and alcohol use disorders are less prevalent among employed than among unemployed and economically inactive people. Among persons with anxiety or alcohol use disorders, service use is more common among the unemployed than among the employed, and this difference is not explained by the severity of the disorder. Future research is warranted to assess whether needs for treatment are adequately met across all employment groups.

\section{References}

1. Murray CJL, Lopez AD. Global mortality, disability, and the contribution of risk factors: global burden of disease. Lancet. 1997;349:1436-42.

2. WHO World Mental Health Survey Consortium. Prevalence, severity, and unmet need for treatment of mental disorders in the World Health Organization World Mental Health Surveys. JAMA. 2004;291:2581-90.

3. Kessler RC, Ormel J, Demler O, Stang PE. Comorbid mental disorders account for the role impairment of commonly occurring chronic physical disorders: results from the National Comorbidity Survey. J Occup Environ Med. 2003;45:1257-66.

4. Lerner D, Adler DA, Chang H, Berndt ER, Irish JT, Lapitsky $\mathrm{L}$, et al. The clinical and occupational correlates of work productivity loss among employed patients with depression. J Occup Environ Med. 2004;46 suppl:S46-55.

5. Wang PS, Beck AL, Berglund P, McKenas DK, Pronk NP, Simon GE, et al. Effects of major depression on moment-intime work performance. Am J Psychiatry. 2004;161:1885-91.

6. Waghorn G, Chant D, White P, Whiteford H. Disability, employment and work performance among people with ICD-10 anxiety disorders. Aust N Z J Psychiatry. 2005;39:55-66.

7. Finnish Centre for Pensions, Social Insurance Institution of Finland. Statistical Yearbook of Pensioners in Finland 2004. Helsinki: Social Protection; 2005.

8. Lindeman S, Hämäläinen J, Isometsä E, Kaprio J, Poikolainen 
$\mathrm{K}$, Heikkinen M, et al. The 12-month prevalence and risk factors for major depressive episode in Finland: representative sample of 5993 adults. Acta Psychiatr Scand. 2000;102:17884.

9. Regier DA, Narrow WE, Rae DS, Manderscheid RW, Locke BZ, Goodwin FK. The de facto US Mental and addictive disorders service system: epidemiologic catchment area prospective 1-year prevalence rates of disorders and services. Arch Gen Psychiatry. 1993;50:85-94.

10. Kessler RC, McGonagle KA, Zhao S, Nelson CB, Hughes M, Eshleman S, et al. Lifetime and 12-month prevalence of DSMIII-R psychiatric disorders in the United States: results from the National Comorbidity Survey. Arch Gen Psychiatry. 1994;51:8-19.

11. Jenkins R, Lewis G, Bebbington P, Brugha T, Farrell M, Gill B, et al. The National Psychiatric Morbidity Surveys of Great Britain-initial findings from the Household Survey. Psychol Med. 1997;27:775-89.

12. Bilj RV, Ravelli A, van Zessen G. Prevalence of psychiatric disorder in the general population: results of the Netherlands Mental Health Survey and Incidence Study (NEMESIS). Soc Psychiatr Psychiatric Epidemiol. 1998;33:587-95.

13. Andrews G, Henderson S, Hall W. Prevalence, comorbidity, disability and service utilisation: overview of the Australian National Mental Health Survey. Br J Psychiatry. 2001;178: 145-53.

14. Pirkola SP, Isometsä E, Suvisaari J, Aro H, Joukamaa M, Poikolainen K, et al. The DSM-IV mood-, anxiety-, and alcohol use disorders and their comorbidity in the Finnish general population: results from the Health 2000 Study. Soc Psychiatry Psychiatric Epidemiol. 2005;40:1-10.

15. WHO International Consortium in Psychiatric Epidemiology. Cross-national comparisons of the prevalence and correlates of mental disorders. Bull World Health Organ. 2000;78:41326.

16. Alonso J, Angermeyer MC, Bernert S, Bruffaerts R, Brugha TS, Bryson H, et al. Prevalence of mental disorders in Europe: results from the European Study of the Epidemiology Mental Disorders (ESEMeD) project. Acta Psychiatr Scand. 2004;109 suppl 420:21-9.

17. Bijl RV, Ravelli A. Psychiatric morbidity, service use, and need for care in the general population: results of the Netherlands Mental Health Survey and Incidence Study. Am J Public Health. 2000;90:602-7.

18. Kraut A, Mustard C, Walld R, Tate R. Unemployment and health care utilization. Scand J Work Environ Health. 2000; 26:169-77.

19. WHO World Mental Health Survey Consortium. Prevalence, severity, and unmet need for treatment of mental disorders in the World Health Organization World Mental Health Surveys. JAMA. 2004;291:2581-90.

20. Lehtonen R, Djerf K, Härkänen T, Laiho J. Modelling complex health survey data: a case study. In: Höglund R, Jäntti M, Rosenqvist G, editors. Statistics, econometrics and society: essays in honour of Leif Norberg. Helsinki: Yliopistopaino; 2003.

21. Aromaa A, Koskinen S, editors. Health and functional capacity in Finland: baseline results of the Health 2000 health examination survey. Helsinki: National Public Health Institute; 2004.
22. Statistics Finland. Statistical yearbook of Finland 2000. Helsinki: Statistics Finland; 2000.

23. Jordanova V, Wickramesinghe C, Gerada C, Prince M. Validation of two survey diagnostic interviews among primary care attendees: a comparison of CIS-R and CIDI with SCAN ICD-10 diagnostic categories. Psychol Med. 2004;34:101324.

24. Wittchen HU, Lachner G, Wunderlich U, Pfister H. Testretest reliability of the computerized DSM-IV version of the Munich-Composite International Diagnostic Interview (MCIDI). Soc Psychiatry Psychiatric Epidemiol. 1998;33:56878.

25. American Psychiatric Association. Diagnostic and statistical manual of mental disorders. 4th edition. Washington (DC): American Psychiatric Association; 1994.

26. Beck AT, Ward CH, Mendelson M, Mock J, Erbaugh J. An inventory for measuring depression. Arch Gen Psychiatry. 1961;4:561-71.

27. Beck AT, Steer RA, Garbin MG. Psychometric properties of the Beck Depression Inventory: twenty years of evaluation. Clin Psychol Rev. 1988;8:77-100.

28. Statistics Finland. Occupational Classification 1997: handbook 14. Helsinki: Statistics Finland; 1999.

29. Dooley D, Fielding J, Levi L. Health and unemployment. Annu Rev Public Health. 1996;17:449-65.

30. Cox T, Leka S, Ivanov I, Kortum E. Work, employment and mental health in Europe. Work Stress. 2004;2:179-85.

31. Bartley M, Owen C. Relation between socioeconomic status, employment and health during economic change, 1973-93. BMJ. 1996;313:445-9.

32. Claussen B, Björndal A, Hjort P. Health and re-employment in a two year follow up of long term unemployed. J Epidemiol Community Health. 1993;47:14-8.

33. de Lange AH, Taris TW, Kompler MAJ, Houtman ILD, Bongers PM. Different mechanisms to explain the reversed effects of mental health on work characteristics. Scand J Work Environ Health. 2005;31(1):3-14.

34. Young A, Klap R, Sherbourne C, Wells K. The quality of care for depressive and anxiety disorders in the United States. Arch Gen Psychiatry. 2001;58:55-61.

35. Simon GE, Fleck M, Lucas R, Bushnell DM, Lido Group. Prevalence and predictors of depression treatment in an international primary care study. Am J Psychiatry. 2004;161:162634.

36. Stein MB, Sherbourne CD, Craske MG, Means-Christensen A, Bystritsky A, Katon W, et al. Quality of care for primary care patients with anxiety disorders. Am J Psychiatry. 2004;161:2230-37.

37. Rytsälä HJ, Melartin TK, Leskelä US, Lestela-Mielonen PS, Sokero TP, Isometsä ET. A record-based analysis of 803 patients treated for depression in psychiatric care. J Clin Psychiatry. 2001;62:701-6.

38. Hämäläinen J, Isometsä E, Laukkala T, Kaprio J, Poikolainen $\mathrm{K}$, Heikkinen M, et al. Use of health services for major depressive episode in Finland. J Affect Disord. 2004;79:105-12.

39. Organisation for Economic Co-operation and Development (OECD). OECD reviews of health systems: Finland. Paris: OECD; 2005 .

Received for publication: 28 December 2005 